Josiane Medeiros de MELLO ${ }^{1}$

Antonio Marcos $\mathrm{ORSI}^{2}$ Robson José de Souza DOMINGUES ${ }^{3}$

Sônia Lucy MOLINARI ${ }^{1}$ Angela Maria Marcone de ARAUJO $^{4}$

Correspondência para:

JOSIANE MEDEIROS DE MELLO, DepartamentodeCiências Morfofisiológicas, Universidade Estadual de Maringá - Av Colombo no 5790 - Zona 7, 87020-900 Maringá,PR,jmello@uem.br

Recebido para publicação: 22/02/2008 Aprovado para publicação: 30/10/2008

\title{
Arquitetura da parede vascular de segmentos torácico e abdominais da aorta de macaco prego (Cebus apella)
}

\author{
1 - Departamento de Ciências Morfofisiológicas da Universidade Estadual de \\ Maringá, Maringá-PR \\ 2 - Departamento de Anatomia da Universidade Estadual Paulista, Botucatu-SP e \\ Universidade de Marília, Marília-SP \\ 3 - Departamento de Anatomia da Universidade do Estado do Pará, Belém-PA \\ 4 - Departamento de Estatística da Universidade Estadual de Maringá, Maringá-PR
}

\section{Resumo}

O segmento torácico da aorta em macaco prego apresentou na túnica íntima uma lâmina elástica interna evidente, estando também presente em todos os segmentos aórticos abdominais analisados nesta espécie. A túnica média aórtica, ao nível torácico, mostrou uma quantidade média de 23,12 lâminas elásticas, tendo disposição circular e oblíqua em relação à luz vascular, e a túnica adventícia apareceu formada por fibras colágenas, dispostas irregularmente entre uma quantidade relativamente menor de fibras elásticas e de fibras musculares lisas. A túnica média do segmento abdominal aórtico, neste primata, observada ao nível supra-renal, apresentou em média 19,12 lâminas elásticas que apareceram relativamente desorganizadas e fragmentadas. Ao nível aórtico infra-renal, foram evidenciadas, na túnica média 11,75 lâminas elásticas, em média, e próximo da emissão das artérias ilíacas comuns a túnica média aórtica tinha cerca de 8,37 lâminas elásticas, as quais estavam entremeadas por fibras musculares lisas e por fibras colágenas que aparentavam aumentar a sua concentração próximo à adventícia. A lâmina elástica externa só foi visível no segmento abdominal aórtico mais distal, ou seja, próximo da emissão das artérias ilíacas comuns.

\section{Introdução}

A aorta de mamíferos é uma artéria que se caracteriza pelo grande desenvolvimento de sua estrutura elástica, presente em toda extensão da túnica média da parede vascular. A elasticidade da parede aórtica, daí decorrente, é um dos principais fatores que permite a acomodação do sangue ejetado pelo ventrículo cardíaco esquerdo, evitando, inclusive, elevações excessivas de pressão arterial. ${ }^{1}$ Acresce-se que as lâminas elásticas aórticas, presentes na túnica vascular média, apresentam-se concêntricas e fenestradas, e entre essas lâminas se encontram fibras colágenas com orientação predominantemente circular e fibras musculares lisas com disposição ondulada. ${ }^{2}$
Palavras-chave:

Aorta.

Morfologia.

Macaco prego.

Primatas.
Padrão arquitetural aórtico com características similares foi confirmado para a aorta de alguns mamíferos $^{2,3,4,5,6}$ e inclusive para o homem ${ }^{7,8}$

Em mamíferos domésticos, e também com destaque para o homem, conhece-se que as variações estruturais sutis observadas na estrutura mural da aorta, em seus diferentes segmentos de trânsito através das cavidades do corpo, apresentam correlações histofisiológicas, ou fisiológicas, com fatores tais como: o regime de pressão arterial sistólica ${ }^{9,10}$, o comportamento mecânico e a visco-elasticidade da parede vascular ${ }^{11,12}$, a arquitetura mio-elástica e a densidade relativa de fibras elásticas nas túnicas da aorta ${ }^{2,4,5,6,8,13}$.

Em virtude da variação da estrutura mural da aorta ao longo de seu trajeto nas 
cavidades torácica e abdominal, este trabalho objetiva descrever as características estruturais segmentares microscópicas da parede da aorta do macaco prego, devido á relativa escassez de dados disponíveis na literatura especializada, sobre estudos específicos da estrutura deste vaso em Cebus apella, um importante primata da fauna brasileira pouco estudado quanto à arquitetura mural dos vasos sangüíneos.

\section{Material e Método}

Neste estudo foram utilizados doze macacos prego (Cebus apella), adultos, sendo 5 machos e 7 fêmeas, doados pelo Centro Nacional de Primatas (CENP), órgão da Fundação Nacional de Saúde, localizado na cidade de Ananindeua, Estado do Pará. Os primatas foram colocados em gaiolas de contenção, imobilizados e pré-anestesiados com quetamina $\left(\right.$ Ketalar $^{\circledR}$ - Ketamine hydrochloride, Lab. Fort Dodge, EUA), por meio de injeção intramuscular na quantidade de $10 \mathrm{mg} / \mathrm{kg}$ de peso corpóreo. Em seguida, os macacos receberam dose letal de quetamina (100 mg/kg), administrada por via intramuscular. Concluída a eutanásia, foram imediatamente perfundidos com solução salina de cloreto de sódio a $0,9 \%$ através de injeção no ventrículo esquerdo do coração.

Após evisceração e exposição dos segmentos torácico e abdominal da aorta, foram coletados segmentos vasculares transversais, com $0,5 \mathrm{~cm}$ de comprimento, em quatro níveis estabelecidos a seguir: (1) segmento torácico da aorta - coletado a $4 \mathrm{~cm}$ cranialmente à passagem da aorta pelo hiato aórtico do diafragma; (2) segmento aórtico abdominal supra-renal - coletado a $1 \mathrm{~cm}$ cranialmente à emissão das artérias renais; (3) segmento aórtico abdominal infra-renal coletado a 1,5 cm caudalmente à emissão das artérias renais e (4) segmento aórtico abdominal terminal - coletado a $1 \mathrm{~cm}$ cranialmente à emissão das duas artérias ilíacas comuns.

Os segmentos vasculares obtidos foram imediatamente imersos em solução a $10 \%$ de formalina neutra tamponada em tampão fosfato $\mathrm{pH} 7,2 ; 0,1 \mathrm{M}$, objetivando o prosseguimento das respectivas preparações histológicas, das quatro porções vasculares. Todos os fragmentos de tecidos foram incluídos em Paraplast, obtendo-se, em seqüência, seis cortes histológicos transversais com 7 a $10 \mathrm{~mm}$ de espessura, para cada segmento. Os cortes foram corados, respectivamente, com: HE, orceína clorídrica de Unna-Taenzer, resorcina-fucsina de Weigert-VanGieson, e tricromicos de Masson, de Mallory e de Calleja. ${ }^{14}$

Para a contagem de lâminas elásticas da túnica média da aorta, nos quatro segmentos vasculares analisados, foram utilizadas duas lâminas histológicas por segmento, sendo as lâminas previamente coradas com orceína clorídrica de Unna-Taenzer. As secções foram analisadas em microscópio de luz, com o uso de uma ocular configurada com um octâmero e utilizando as objetivas de 20x e de 40x. Em cada parte do octâmero, foram contados os números de lâminas elásticas, a partir dos quais foram calculadas as médias aritméticas e os respectivos desvios padrão. Os dados quantitativos, obtidos por meio da contagem das lâminas elásticas da aorta, foram analisados mediante teste estatístico de análise de variância e pelo teste de Tukey. Todas as conclusões foram analisadas ao nível de 5\% de significância, e os intervalos de confiança foram construídos ao nível de 95\%.

\section{Resultados}

A túnica íntima dos segmentos torácico e abdominais da aorta de macaco prego apresentou uma lâmina elástica interna evidente, presente em toda a circunferência da parede vascular (Figuras 1b, 2b, 3a, 4a). A estrutura da túnica aórtica média, nesta espécie, mostrou lâminas elásticas com distribuição variável, no segmento torácico e nos três segmentos abdominais (Tabela 1), sendo entremeadas por fibras musculares lisas e fibras colágenas. No segmento aórtico torácico, a túnica média mostrou um número relativamente maior de lâminas elásticas sendo, em média, de 23,12. Essas lâminas elásticas tinham pouco espaço entre elas; se mostraram organizadas e com disposição circular e oblíqua, em relação ao lúmen vascular, estando algumas delas ligadas 

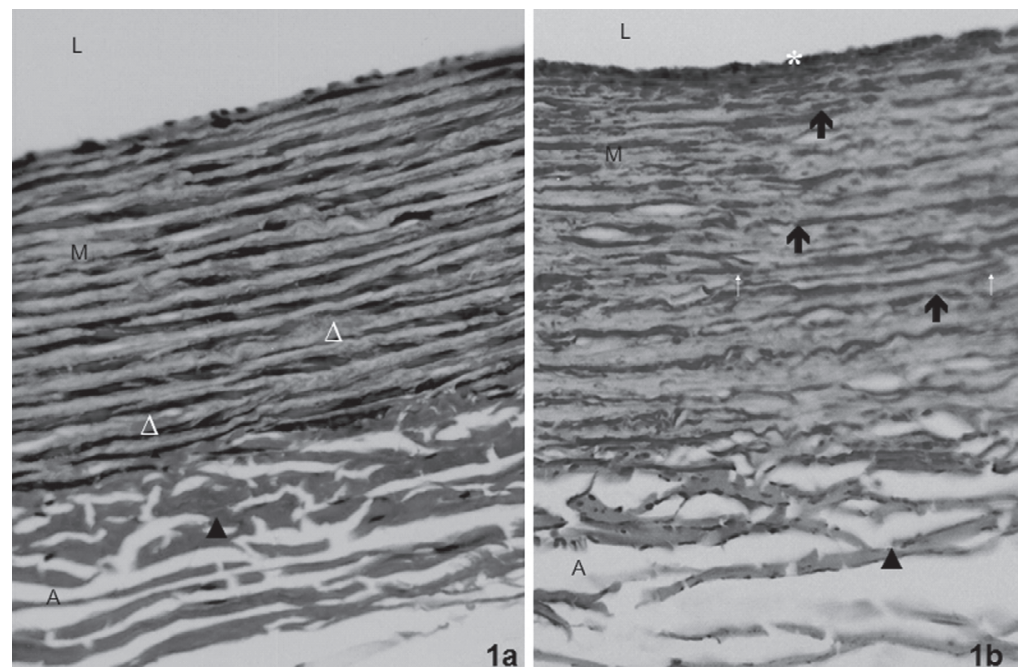

Figura 1 - Arquitetura da parede vascular de segmentos torácico da aorta de macaco prego (Cebus apella). São indicados: luz vascular (L), túnica média $(\mathrm{M})$, túnica adventícia $(\mathrm{A})$, membrana elástica limitante interna $(*)$, lâminas elásticas da túnica média $(\boldsymbol{\uparrow})$, fibras colágenas da túnica média $(\Delta)$, trabéculas de fibras elásticas da túnica média $(\uparrow)$ e, fibras colágenas da túnica adventícia $(\boldsymbol{\Delta})$.

(a - tricrômico de Masson, b - orceína clorídrica- 200x)

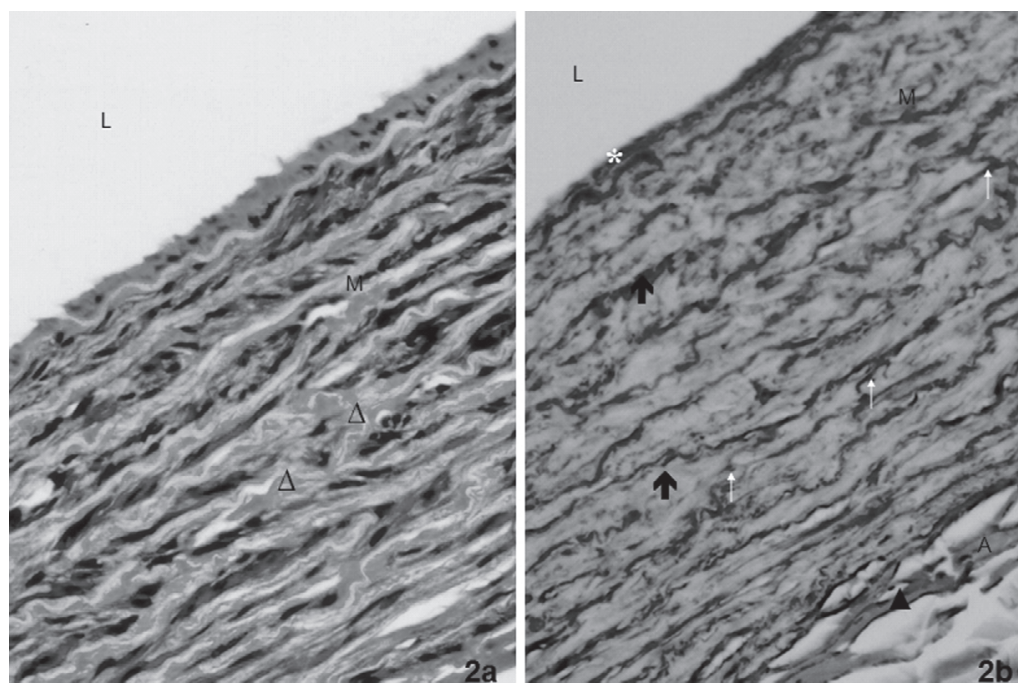

Figura 2 - Arquitetura da parede vascular de segmentos abdominais (supra-renal) da aorta de macaco prego (Cebus apella). São indicados: luz vascular (L), túnica média ( $M$ ), túnica adventícia (A), membrana elástica limitante interna $(*)$, lâminas elásticas da túnica média $(\boldsymbol{\uparrow})$, fibras colágenas da túnica média $(\Delta)$, trabéculas de fibras elásticas da túnica média $(\uparrow)$ e, fibras colágenas da túnica adventícia $(\boldsymbol{\Lambda})$.

(a - tricrômico de Calleja; b - Weigert Van Gieson - 200x)

entre si por meio de trabéculas delgadas de fibras elásticas, orientadas em sentido diagonal (Figura 1b).
Na túnica média do segmento aórtico abdominal supra-renal havia, em média, 19,12 lâminas elásticas (Tabela 1), porém essas

Tabela 1 - Resultado da distribuição do número de lâminas elásticas da túnica média da aorta, ao longo do trajeto torácico-abdominal, de 12 macacos prego - Pará - 2002

\begin{tabular}{lllll}
\hline Segmentos aórticos & torácica & $\begin{array}{l}\text { abdominal } \\
\text { supra-renal }\end{array}$ & $\begin{array}{l}\text { abdominal } \\
\text { infra-renal }\end{array}$ & $\begin{array}{l}\text { abdominal } \\
\text { terminal }\end{array}$ \\
\hline Média e desvio padrão & $23,12 \pm 2,35$ & $19,12 \pm 1,80$ & $11,75 \pm 2,86$ & $8,37 \pm 0,74$ \\
\hline
\end{tabular}



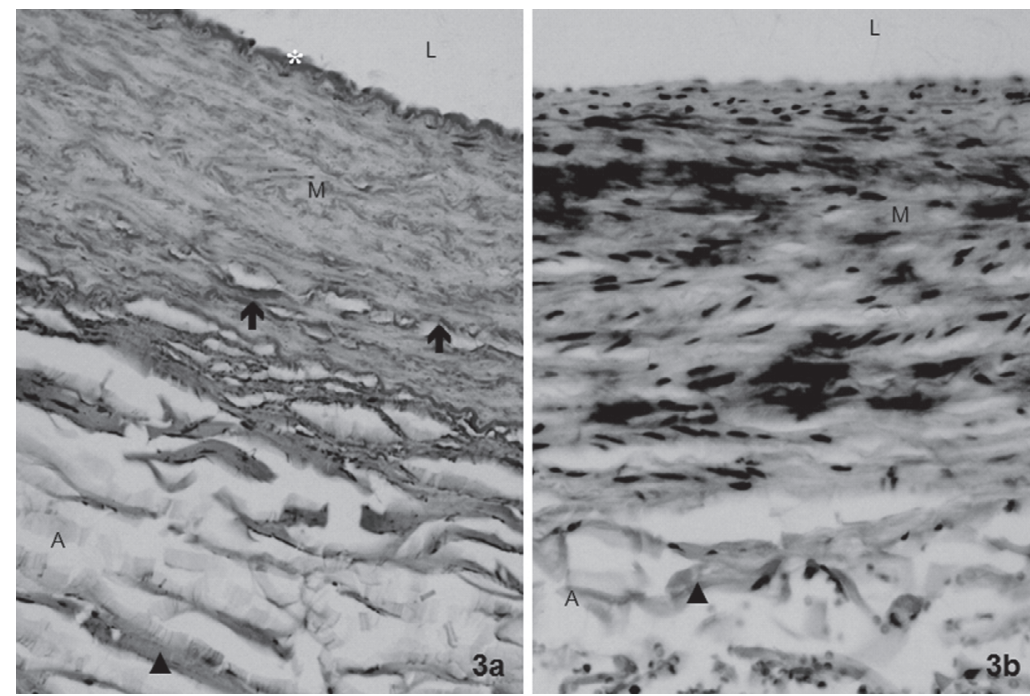

Figura 3 - Arquitetura da parede vascular de segmentos abdominais (infra-renal) da aorta de macaco prego (Cebus apella). São indicados: luz vascular (L), túnica média $(\mathrm{M})$, túnica adventícia $(\mathrm{A})$, membrana elástica limitante interna $(*)$, lâminas elásticas da túnica média $(\boldsymbol{\uparrow})$ e, fibras colágenas da túnica adventícia $(\boldsymbol{\Lambda})$. (a - tricrômico de Calleja; b - Weigert Van Gieson - 200x)

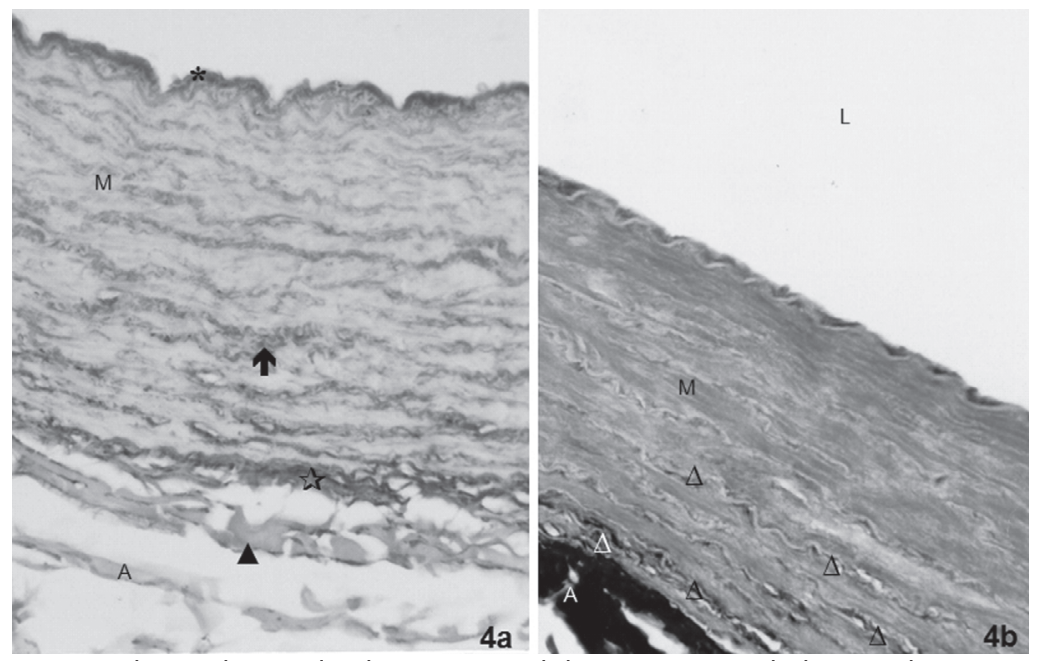

Figura 4 - Arquitetura da parede vascular de segmentos abdominais (terminal) da aorta de macaco prego (Cebus apella). São indicados: luz vascular (L), túnica média (M), túnica adventícia (A), membrana elástica limitante interna $(*)$, lâminas elásticas da túnica média $(\boldsymbol{\uparrow})$, fibras colágenas da túnica média $(\Delta)$, lâmina elástica externa (荬), e, fibras colágenas da túnica adventícia $(\boldsymbol{\Delta})$.

(a - orceína clorídrica; b - tricrômico de Mallory - 200x)

mostraram entre si um espaçamento relativamente maior, aparecendo mais desorganizadas e fragmentadas, quanto ao segmento aórtico torácico. As trabéculas elásticas diagonais, interligantes das lâminas elásticas, mostraram-se relativamente mais definidas ao nível supra-renal, propiciando um aspecto lamelar elástico entrelaçado (Figura 2b). Nos espaços interlamelares elásticos, dos segmentos aórticos torácico e abdominal supra-renal, observaram-se fibras musculares lisas formando um sistema mio-elástico, entremeado por fibras colágenas (Figuras 1a, 1b, 2a, 2b).

Na porção abdominal aórtica infrarenal, a túnica média apresentou lâminas elásticas desorganizadas e menos freqüentes, ocorrendo, em média, 11,75 lâminas elásticas (Tabela 1). Essas lâminas apareceram entrelaçadas entre si por meio de trabéculas 
elásticas (Figura 3a), assim como o padrão mio-conjuntivo antes descrito foi também observado (Figura 3b).

O segmento abdominal terminal da aorta de macaco prego, próximo da emissão das duas artérias ilíacas comuns, mostrou, na túnica média, a presença de poucas lâminas elásticas, tendo, em média, 8,37 lâminas (Tabelas 1). Essas eram entremeadas por uma quantidade relativamente maior de fibras musculares lisas e por fibras colágenas formando o tecido mio-estromal ${ }^{2}$, o qual aparentou aumentar a sua concentração próximo à túnica adventícia (Figura $4 \mathrm{~b}$ ). A lâmina elástica externa estava presente na estrutura mural aórtica deste segmento terminal (Figura 4a), porém não foi observada nos demais segmentos aórticos precedentes.

Quanto à túnica adventícia do segmento torácico e dos três segmentos abdominais, analisados na parede da aorta de macaco prego, ela mostrou uma disposição relativamente pouco organizada dos seus elementos estruturais. As fibras colágenas apareceram irregularmente dispostas entre poucas fibras elásticas e poucas células musculares lisas, aí encontradas (Figuras 1a, 2b, 3b, 4a).

As análises estatísticas, realizadas por meio do método de análise de variância (ANOVA) ao nível de 5\% de significância, apresentaram um "P-value" zero, mostrando que houve evidência de que, em pelo menos num dos quatro segmentos avaliados (provavelmente ao nível torácico), o número médio de lâminas elásticas da túnica aórtica média, de macaco prego, apresentou diferença significativa. Após a aplicação do teste de Tukey, concluiu-se que todas os segmentos aórticos analisados, nesta espécie, apresentaram diferenças significativas quanto ao número médio de lâminas elásticas, presentes na túnica média da parede vascular (Tabela 2).

\section{Discussão}

Na túnica íntima da aorta de macaco prego observou-se em todas, uma lâmina elástica interna evidente, disposta uniformemente em toda a circunferência vascular, o que é comum para a arquitetura aórtica em diferentes classes de vertebrados. 2, 4, 5, 6, 8, 13, 15, 16 Alguns trabalhos mostraram que a túnica íntima não só da aorta, conforme os autores citados, mas também de outras artérias de médio calibre, cuja estrutura mural foi estudada em outros mamíferos ${ }^{17,18,19,20}$, apresentou uma lâmina elástica interna marcante, a qual funcionaria como um importante mecanismo para reserva de visco-elasticidade da parede arterial. ${ }^{21}$

A túnica média dos segmentos torácico e abdominais da aorta de macaco prego (Cebus apella), mostrou-se estruturada, de modo geral, por fibras musculares lisas, fibras colágenas e fibras elásticas, sendo essas disposição predominantemente lamelar; observando-se número e distribuição diferentes de lâminas elásticas nos diferentes segmentos da parede vascular como antes fora relatada na aorta de outros mamíferos. ${ }^{3,}$ 4, 5, 6,22 Ademais, foi observada, na arquitetura mural da média aórtica de Cebus apella uma disposição alternada entre as lâminas elásticas; as fibras musculares lisas e as fibras colágenas como foi descrita na aorta humana. ${ }^{8}$ Essa alternância dos elementos estruturais, já caracterizados como mio-estromais ${ }^{5,11}$, tende a ser mais marcante, na túnica média, em segmentos mais distais da aorta, ao nível

Tabela 2 - Resultado da análise da ANOVA seguido do teste Tukey, referente a contagem do número médio de lâminas elásticas, analisadas ao longo do trajeto torácico-abdominal, de 12 macacos prego Pará - 2002

\begin{tabular}{ccc}
\hline $\begin{array}{c}\text { Hipótese } \\
\text { estatística }\end{array}$ & $\begin{array}{c}\text { Resultado do teste } \\
\text { estatístico }\end{array}$ & Conclusão \\
\hline $\begin{array}{c}\text { Semelhança dos } \\
\text { perfis }\end{array}$ & $\theta=0,95 \quad(\mathrm{P}<0,05)$ & $\begin{array}{c}\text { não existe número semelhante entre as lâminas elásticas da túnica média } \\
\text { nos } 4 \text { segmentos analisados da aorta de macaco prego }\end{array}$ \\
\hline $\begin{array}{c}\text { Diferença entre os } \\
\text { segmentos aórticos }\end{array}$ & $\mathrm{F}=82,519(\mathrm{P}<0,00)$ & torácica $\neq$ abdominal supra-renal $\neq$ abdominal infra-renal $\neq$ abdominal terminal \\
\hline
\end{tabular}


abdominal, como se descreveu na aorta de alguns mamíferos ${ }^{3,4,5,6}$, embora sem a caracterização da diminuição expressiva de lâminas elásticas, indo do segmento suprarenal em direção ao segmento aórtico terminal (Tabela. 1), descrita neste estudo.

A diminuição do número de lâminas elásticas presentes na estrutura da camada média, nos segmentos mais distais da aorta, ao nível abdominal, observada no macaco prego e noutros mamíferos estudados $3,4,5,6$, talvez tenha correlação com a observação de que na hemodinâmica da aorta humana se nota uma pequena diminuição relativa da pressão arterial sistólica no segmento aórtico abdominal infrarenal ${ }^{9}$. Correlacionou-se, inclusive, que em função da diminuição relativa de lâminas elásticas, presentes na porção terminal da aorta humana, haveria uma possível correlação morfofuncional com a patofisiologia de aneurismas, aparentemente prevalentes ao nível da aorta abdominal. ${ }^{23}$

Song e Roach ${ }^{16}$, por outro lado, descreveram que a quantidade de lâminas e de fibras elásticas da túnica média aórtica varia, dependendo do porte do animal, e que o padrão de distribuição desse tecido elástico, também é variável desde a íntima até a adventícia. Aparentemente o macaco prego por ser um primata de pequeno porte tenderia a ter número menor de lâminas elásticas, ao longo da média aórtica, comparativamente com mamíferos de maior porte, como o homem por exemplo, mas efetivamente o que se notou, no macaco, foi um número maior de lâminas elásticas no segmento torácico onde o impacto da pressão sistólica ventricular é maior, em detrimento de uma diminuição progressiva, e significativa (Tabela 2), nos segmentos mais distais do trânsito abdominal da aorta, para o qual a hipótese da diminuição da pressão intravascular a este nível foi proposta anteriormente, com base em observações fisiológicas feitas na aorta humana. ${ }^{9}$

As lâminas elásticas encontradas na túnica aórtica média ao nível supra-renal mostraram-se inter-reunidas por trabéculas de fibras elásticas com sentido diagonal, conferindo a essas lâminas um aspecto entrelaçado. Essa disposição elástica em que uma lamela elástica se entrelaça e se ancora na lamela adjacente por trabéculas elásticas fora caracterizada como a constituição de unidades lamelares da túnica aórtica média atuando como entidades fundamentais na conduta mecânica da aorta. ${ }^{19}$ A este conceito acrescentou-se a caracterização ao nível de "unidade mural fundamental" da camada média aórtica a ocorrência de unidades mioestromais (mio-fibro-elásticas ${ }^{2}$ ), de papel relevante na visco-elasticidade da parede arterial 11. A lâmina elástica externa nos segmentos aórticos torácicos e abdominais, supra-renal e infra-renal, não foi evidenciada, provavelmente por se mesclar com as lâminas elásticas da túnica média. Porém, ao nível terminal da aorta, próximo da emissão das artérias ilíacas comuns, observou-se a presença de uma lâmina elástica externa evidente, talvez decorrendo da diminuição relativa do número de lâminas elásticas da túnica média, neste nível (Tabela 1).

Quanto à estrutura da túnica adventícia da parede da aorta de macaco prego, apresentou-se constituída predominantemente por colágeno com disposição irregular, sendo que poucas fibras elásticas e fibras musculares lisas foram observadas. Um padrão estrutural adventicial aórtico similar foi descrito para outros mamíferos ${ }^{2,4,5}$, inclusive o homem ${ }^{24}$, e também para outras classes de vertebrados ${ }^{15}$.

\section{Conclusão}

A túnica média da parede da aorta de macaco prego, em seu segmento abdominal, apresentou diminuição expressiva no número de lâminas elásticas, desde o nível infra-renal até próximo da emissão das artérias ilíacas comuns, havendo também certa diferenciação no padrão de distribuição e inter-relação dessas fibras elásticas com outros componentes mioconjuntivos da parede vascular, nos quatro segmentos vasculares estudados. $\mathrm{O}$ componente lamelar elástico foi maior na túnica média dos segmentos aórticos torácico e abdominal supra-renal, nesta espécie. Análises estatísticas, realizadas sobre o número de lâminas elásticas presentes em cada segmento 
aórtico analisado, mostraram que todos os segmentos aórticos de macaco prego apresentaram diferenças significativas quanto ao número dessas lâminas presentes na túnica média, com possíveis correlações morfofuncionais em termos de viscoelasticidade da parede vascular e do papel hemodinâmico da aorta.

\section{Architectural features of the aortic wall of Cebus apella monkey at the thoracic segment and at some abdominal segments: a light microscope study}

\section{Abstract}

The intimal layer of the thoracic and abdominal aortic segments of Cebus apella monkey presented an evident inner elastic lamina. The medial layer of the thoracic aorta segment showed a basic lamellar elastic pattern having a medium average of 23.12 lamellae per analyzed cut sections, which appeared disposed circular and oblique relatively to the aortic lumen. The aortic adventitial layer, at this level, was formed mainly by collagen fibers, irregularly disposed between elastic fibers and smooth muscle cells. The aortic abdominal portion, in this monkey, at the suprarenal level presented a medium number of 19.12 elastic lamellae which showed a relatively disorganized and broken up pattern. At the infrarenal level the aortic medium layer showed a medium average of 11.75 elastic lamellae and next to the emission of the internal iliac arteries it was found only a middle average of 8.37 elastic lamellae intermingled with smooth muscle cells and collagen fibers whose concentration seemed to be increased next to the adventitial layer. The external elastic lamina was only present in the more distal aortic segment near to the emission of the internal iliac arteries.

\section{Referências}

1 SIMIONESCU, N.; SIMIONESCU, M. O sistema cardiovascular. In: WEISS, L., GREEP, R. O. Histologia. 4. ed. Rio de Janeiro: Guanabara Koogan, 1981. p. 323-339.

2 MELLO, J. M.; ORSI, A. M.; PADOVANI, C. R.; MATHEUS, M. M.; TORREJAIS, M. M.; RIBEIRO, A. A. C. M. Some segmental structural features of the aortic wall of domestic chicken (Gallus domesticus). Brazilian Journal of Veterinary Research and Animal Science, $v$. 40, p. 163-169, 2003. Supplement.

3 AWAL, M. A. Morphometrical changes of the arterial walls of main arteries from heart to the abdominoinguinal mammary glands of rats from virgin through pregnancy, lactation and post-weaning. Journal of Veterinary Medical Science, v. 57, p. 251-256, 1995.

4 ORSI, A. M; STEFANINI, M. A.; CROCCI, A. J.; SIMÕES; RIBEIRO, A. A. C. M. Some segmental features on the structure of the aortic wall of the dog. Anatomia, histologia, embryologia, v. 33, n. 3, p. 131-134, 2004.

5 PEASE, D. C.; PAULE, W. J. Electron microscopy of elastic arteries; the toracic aorta of the rat. Journal of Ultrastructure Research, v. 3, p. 469-483, 1960.
Key words:

Aorta.

Morphology.

Cebus apella monkey. Primates.
6 WILLIAMS, P. L. Angiologia. In: WILLIAMS, P. L.; WARWICK, R.; DYSON, M.; BANNISTER, L. H. Gray Anatomia. 37. ed. Rio de Janeiro: Guanabara Koogan, 1995. v.1, cap.6, p. 635-807.

7 HAM, A. W.; CORMACK, D. H. Sistema circulatório. In: HAM, A. W.; CORMACK, D. H. Histologia. Rio de Janeiro: Guanabara Koogan, 1983. cap.19, p. 555-575.

8 CLARK, J. M.; GLAGOV, S. Transmural organization of the arterial media: the lamellar unit revisited. Arterioscleorosis, v. 5, n. 1, p. 19-34, 1985.

9 HOYES, A. D. Myodifferentiation in the carotid artery of the adult sheep: an ultrastructural study. Acta Anatomica, v. 88, n. 1, p. 34-43, 1974.

10 MELLO, J. M. Estrutura da aorta e da artéria ilíaca externa de cobaio: aspectos comparativos com o rato albino e ave doméstica, 1999. 83 f. Tese (Doutorado em Anatomia) - Instituto de Biociências, Universidade Estadual Paulista, Botucatu, 1999.

11 DINGEMANS, K. P.; JANSEN, N.; BECKER, A. E. Ultrastructure of the normal human aortic media. Virchows Archives, v. 392, n. 2, p. 199-216, 1981.

12 STEHBENS, W. E. Structural and architectural changes during arterial development and the role of hemodynamics. Acta Anatomica, v. 157, n .4 p. 261- 
274, 1996.

13 MELLO, J. M.; ORSI, A. M.; PADOVANI, C. R.; MATHEUS, S. M.; ELEUTERIO, M. L. Structure of the aortic wall in the guinea pig and rat. Brazilian Journal of Morphological Science, v. 21, p. 35-38, 2004.

14 LILLIE, R. D. Histopathologic technic and practical histochemistry. $3^{\text {rd }}$ ed. New York: McGraw-Hill, 1965. 715 p.

15 SILVA, I.; FRANCO, S. L.; CONEGERO, C. I. Noções sobre o organismo humano e utilização de plantas medicinais. 2. ed. Cascavel: Assoeste, 1995. p. 203.

16 SONG, S. H.; ROACH, M. R. A. A morphological comparison of aortic elastin from five species as seen with the scanning electron microscope. Acta Anatomica, v. 123 , n. 1, p. 45-50, 1985.

17 LEE, R. M. K. W. Morphology of cerebral arteries. Pharmacology and Therapeutics, n. 1, p. 149-173, 1995.

18 MACWEENEY, S. T. R. Pathophysiology of aneurysm disease. In: Abdominal aortic aneurysm: report of a meeting of physicians and scientistis. University College, London Medical School. Lancet, v. 341, p. 215-220, 1993.

19 REES, P. M. Electron microscopic observations on the architecture of the carotid arterial walls, with special reference to the sinus portion. Journal of Anatomy, v. 103, n. 1, p. 35-47, 1968.

20 SARRO, C. Estudo evolutivo da anatomia do sistema circulatório e análise histológica da aorta em diferentes espécies de vertebrados. 2007. 27 f. Monografia (Especialização em Ciências Biológicas) - Departamento de Ciências Morfofisiológicas, Universidade Estadual de Maringá, Maringá, 2007.

21 VIEGAS, K. A.; ORSI, A. M.; MATHEUS, S. M. M.; FRANCIAFARJE, L. A. D.; ORSI, D. C.; MELLO, J. M. Características estructurales de la aorta del conejo (Oryctolagus cuniculus). Revista Chilena de Anatomía, v. 19, n. 2 , p. 131-137, 2001.

22 PIFFER, C. R.; FREITAS, V.; ZORZETTO, N. L. Observaciones microscópicas de la pared de la arteria carótida interna en los segmentos cervical y petroso. Anatomia, Histologia, Embryologia, v. 9, n. 1, p. 44-51, 1980.

23 MELBIN, J.; DETWEILER, D. K. Sistema cardiovascular e fluxo sangüíneo. In: SWENSON, M. J.; REECE, W. O. Dukes fisiologia dos animais domésticos. Rio de Janeiro: Guanabara Koogan, 1996. cap. 5, p. 57-222.

24 WOLINSKY, H.; GLAGOV, S. A lamellar unit of aorta medial structure and function in mammals. Circulation Research, v. 20, n. 1, p. 99-111, 1967. 